\title{
Recrystallisation-Assisted Creep of an Austenitic Fe-Ni Alloy Under Low Stresses After Hot Deformation
}

\author{
Minghao Zhang ${ }^{\mathrm{a}, \mathrm{b} 1}$, Anne-Françoise Gourgues-Lorenzon ${ }^{\mathrm{a} 2}$, Esteban P. Busso ${ }^{\mathrm{a} 3}$, Haiwen Luo \\ and Mingxin Huang ${ }^{\mathrm{d}}$
}

${ }^{a}$ MINES ParisTech, PSL Research University, Centre des matériaux, UMR CNRS 7633, B.P.87, 91003 Evry Cedex, France

${ }^{\mathrm{b}}$ ArcelorMittal Research, Voie Romaine-BP 30320, 57283 Maizières-lès-Metz Cedex, France

${ }^{\mathrm{c}}$ School of Metallurgical and Ecological Engineering, University of Science and Technology Beijing, Xue Yuan Lu 30, Haidian, 100083 Beijing, China

${ }^{\mathrm{d}}$ Department of Mechanical Engineering, The University of Hong Kong, Pokfulam Road, Hong Kong, China

\begin{abstract}
Static and meta-dynamic recrystallisation are known to take place in some steels under low tensile stresses during thermo-mechanical processes, e.g. between rolling stands in a hot strip finishing mill. The main objective of the present work is to understand the mechanisms responsible for the recrystallisation-assisted visco-plastic deformation in a hot worked iron-nickel austenitic alloy subjected to low stress levels at high temperatures. To that purpose, the recrystallisation kinetics of the alloy was first quantified from stress relaxation, interrupted creep and double-hit compression tests, followed by a microstructural study. The evolutions of strain both in the recrystallising and in the fully recrystallised microstructures were quantified. One of the most original aspects of this work is the experimental verification that the acceleration of the viscoplastic deformation of a recrystallising material is unequivocally and intrinsically associated with the on-going recrystallisation phenomenon itself. For the austenitic alloy of interest, the most important contribution to this deformation enhancement was found to arise from the deformation of newly recrystallised grains in the primary creep regime. Finally, it is also shown that this recrystallisation-assisted deformation can be qualitatively predicted with acceptable accuracy using a relatively simple, physics-inspired constitutive model.
\end{abstract}

Keywords: static recrystallisation; mechanical properties; high temperature deformation; austenitic steel; primary creep

\footnotetext{
${ }^{1}$ Present address: Yantai Manoir Heat Resistant Alloys Co., Ltd., No. -1, Zhichu South Road, Zhifu District, Yantai, China. 264000, minghao.zhang@manoir.eu.com

${ }^{2}$ Corresponding author. Email: anne-francoise.gourgues@mines-paristech.fr

${ }^{3}$ Present address: Department of Mechanical Engineering, Imperial College London, Exhibition Road, London SW7 2AZ, UK, e.busso@ic.ac.uk
} 


\section{Introduction}

In thermomechanical forming processes, the accuracy of the product dimensions strongly depends on its viscoplastic deformation during processing. This deformation is associated with considerable microstructural changes, in particular due to recrystallisation. For example, viscoplastic deformation is known to accompany recrystallisation between stands during the finishing stages of a hot rolling process [1-7] when hot deformed strips are subjected to low tensile stresses (typically, a few tens of megapascals). Poirier et al. [8] found that thermal contraction could only partially account for the total strip width reduction between finishing hot-rolling stands. The prediction of the remaining contraction was underestimated by existent steady-state creep models. Thus, a better understanding and prediction of viscoplastic deformation, in particular during recrystallisation, is a key issue for an accurate control of product dimensions in a number of hot forming-related processes. Typical loading conditions, especially between the first two stands of a hot strip finishing mill, can be considered as (e.g., [8-13]): a strip temperature of the order of $950-1050^{\circ} \mathrm{C}$, a strain rate of $10 \mathrm{~s}^{-1}$ with $30-50 \%$ reduction applied in the first stand, and an interpass tensile stress (applied through automatic control of the loopers) of 10$30 \mathrm{MPa}$. The corresponding interpass time is rather long (a few seconds [8]), as for mass balance reasons, the velocity of the strip there is much lower than at the mill exit.

Viscoplastic theories [14-16] already addressed the considerable deformation which accompanies dynamic recrystallisation such as that reported in lead [17]. However, static recrystallisation-assisted viscoplastic deformation under low stresses has attracted very little attention from the metallurgy community and so far there are only a few experimental studies highlighting this issue. Early relevant observations were reported on lead by Gifkins [18], on both gold and nickel by Hardwick et al. [19] and on nickel by Richardson et al. [20]. All of them pointed out abrupt increases in creep rate during steady state creep due to the occurrence of static recrystallisation. Gifkins [18] did not succeed in monitoring recrystallisation by direct microstructural observations but proposed that creep acceleration resulted from the contribution of softer, freshly recrystallised material to primary creep. However, no supporting experimental evidence was provided. Similar results were reported by Cheng et al. [21] and Ginter et al. [22-23] to explore the Harper-Dorn creep regime in coarse grained, high-purity lead and aluminium, respectively. However, the particular geometry of their creep specimens required further mechanical analysis [24]. Abrupt accelerations in creep occurred for specimens showing a recrystallised microstructure from post mortem examinations. Recently, the recrystallisation effects on viscoplasticity have been reported on different metallic alloys [19, 20, 25-28]. Sagging tests (i.e., cantilever bending tests while heating, then holding the specimen at high temperature for some time) on cold-rolled aluminium alloy samples performed by Hutchinson et al. [27], were carried out. Subsequent microstructural observations after interrupted tests revealed a rather rapid acceleration of creep strain during recovery in the $200^{\circ} \mathrm{C}-300^{\circ} \mathrm{C}$ temperature range and, even more rapidly, during 
recrystallisation in the $300^{\circ} \mathrm{C}-350^{\circ} \mathrm{C}$ temperature range. In these experiments, the creep behaviour of recrystallised material was found to strongly depend on the initial microstructure and on the stress state. However, recrystallisation kinetics was not determined, thus the relative creep contributions from the recrystallised material to that of the recrystallising material could not be ascertained. Cold worked extra-low carbon steel [25] and Fe-3\%Si [26] specimens showed additional deformation between the $600^{\circ} \mathrm{C}-1000^{\circ} \mathrm{C}$ range due to recrystallisation when heated up under externally applied stresses. This deformation enhancement mechanism will henceforth be referred to as "recrystallisation-induced plasticity". Two explanations have been proposed for such mechanism: (i) accelerated diffusion of atoms during recrystallisation along migrating grain boundaries (acceleration of Coble creep) [25], and (ii) oriented motion of defects along the applied stress direction during recrystallisation [26]. Furthermore, the work reported in [28] also provided experimental evidence of the existence of recrystallisation-induced plasticity in both the austenite and ferrite phases of the steel through creep tests and dilatometric measurements. These observations were believed to result mainly from atomic diffusion during recrystallisation along the applied stress direction. In the above studies, the contribution of deformation from softer, freshly recrystallised material was not considered to be significant. Nevertheless, in spite of all the above investigations, there is still no direct and convincing experimental evidence to quantitatively associate the deformation enhancement during recrystallisation with the recrystallisation kinetics and microstructural evolution.

The present work aimed at providing direct evidence of recrystallisation-induced plasticity under low stresses, as well as identifying and quantifying the dominant underlying mechanism(s). The recrystallisation kinetics and mechanisms were first characterised in the stress and temperature range of interest. Then, the contribution of recrystallisation to viscoplastic deformation under stress, i.e., the recrystallisation-assisted plasticity phenomenon was evidenced and quantified by comparing the viscoplastic deformation evolution between (i) a recrystallising material and (ii) a fully recrystallised material under the same loading conditions.

To this aim, a Fe-36\%Ni (Invar) alloy was selected as a model material. The stability of the austenite phase down to room temperature enabled the microstructural observations made to be representative of the microstructure at the end of hot deformation stages. In this alloy, dynamic recrystallisation has been reported to improve the resistance to hot intergranular cracking around $700-1000^{\circ} \mathrm{C}$, due to segregation issues [29-31] that can be controlled with the help of microalloying elements [32]. Its nonrecrystallisation temperature (i.e., the temperature below which no dynamic recrystallization is observed) was first reported by Cho et al. [33] on a Fe- $37 \% \mathrm{Ni}-0.53 \% \mathrm{Mn}-0.15 \% \mathrm{Cr}$ chemistry by the fractional softening method. It ranged between 1000 and $1020^{\circ} \mathrm{C}$ (for $10-20 \%$ deformation per hot torsion pass at $0.3 \mathrm{~s}^{-1}$ ), yet with no associated microstructural observation. The high-temperature flow behaviour of a Fe-36Ni-type alloy was first reported [34] on a coarse-grained Fe-37\%Ni-0.02\%Mn- 
$0.03 \% \mathrm{Si}$ subjected to homogenization at $1200^{\circ} \mathrm{C}$, then to isothermal compression at $850-1100^{\circ} \mathrm{C}$, for strain rates between $10^{-2}$ and $10 \mathrm{~s}^{-1}$. From the reported electron backscatter diffraction (EBSD) maps, only the high temperature, low strain rate conditions were found to lead to continuous dynamic recrystallisation; post-dynamic and static recrystallisation phenomena were not addressed in their paper. The static recrystallisation behaviour and mechanisms of the Fe-36\%Ni alloy family have been widely characterised after cold working and annealing at temperatures between $600^{\circ} \mathrm{C}$ and $900^{\circ} \mathrm{C}[35-$ 37]. In particular, heavy cold rolling has been shown to favour early nucleation of recrystallised, cubeoriented grains from the strongly recovered cube-oriented grains of the deformed microstructure [37]. Their larger size and lower stored energy then lead to preferential growth of these grains and to the development of a strong cube texture, desired for applications such as thin sheets (e.g., shadow masks) [37-41]. Other cold forming routes, such as less severe cold rolling or accumulative roll bonding [42], as well as multiple twinning during recrystallisation [39], are known to lead to less marked textures $[36,39]$ and different cold formability properties (e.g., resistance to earing in deep drawing) as quantified by their Lankford coefficient [36].

\section{Experimental Details}

The material under study was a hot-rolled, $\mathrm{Nb}$-free $\mathrm{Fe}-36 \% \mathrm{Ni}-0.35 \% \mathrm{Mn}-0.15 \% \mathrm{Si}$ (in wt.\%) austenitic alloy having an annealed equiaxed microstructure with an average grain size of $50 \pm 10 \mu \mathrm{m}$.

All compression tests reported in the present work were performed using a Gleeble 1500D thermomechanical simulator in primary vacuum conditions and $10 \mathrm{~mm}$ diameter cylindrical specimens of $15 \mathrm{~mm}$ in height. Thermocouples were spot-welded at mid-height for temperature monitoring and control. Specimen height and mid-height diameter changes were respectively measured through the displacement of anvils in the compression direction and by means of a diametral extensometer. The accuracy of diameter measurements (resolution of $0.1 \mu \mathrm{m}$ ) was better than that from the displacement of anvils, the latter being affected by thermal expansion of the anvils. A lubricating graphite foil was placed between the specimen and each of the anvils to limit specimen barrelling through a reduction of the contact area friction. Growth of the oxidation layer (less than $60 \mu \mathrm{m}$ in thickness at the end of the tests) was estimated to contribute to less than $1 \%$ of the total diametral creep strain, thus, it was not further considered in what follows.

To enable recrystallisation from a well-controlled hot-worked state, all tests involved a predeformation stage followed by various thermomechanical stages. During the pre-deformation stage, the specimens were first heated up to a given temperature (between 850 and $1050^{\circ} \mathrm{C}$ ) at $30^{\circ} \mathrm{C} / \mathrm{s}$ under a very low compressive stress, $\sigma_{\text {hold }}$, (approximately $4.5 \mathrm{MPa}$, in order to hold the specimen) and then 
held for $10 \mathrm{~s}$ for temperature homogenisation. They were then compression loaded under displacement control with a constant strain rate up to a $30 \%$ axial strain, which is known to be the critical deformation level to trigger dynamic recrystallisation in a similar $\mathrm{Fe}-32 \% \mathrm{Ni}$ alloy at $1000^{\circ} \mathrm{C}$ and $2 \times 10^{-3} \mathrm{~s}^{-1}$ [43], and in a Fe-36\% Ni alloy [34] in conditions close to those investigated in the present work. After pre-deformation, either the displacement of the anvils was kept constant (see stress relaxation tests in Fig. 1a) or the specimens were unloaded down to a given (low) constant compressive load. For the creep tests, see Fig. 1b, this load was kept constant until the end of the test; the corresponding engineering creep stress, $\sigma_{\text {creep }}$, ranged between 18 and $72 \mathrm{MPa}$. Note that the twosecond unloading stage, right after point $\mathrm{P}$ in Figs. 1b-d was taken into account when analysing the creep tests at $950^{\circ} \mathrm{C}$ and $1050^{\circ} \mathrm{C}$, as recrystallisation takes place rapidly at these temperatures. In the so-called "delayed creep tests" (see Fig. 1c), a constant, low compressive stress (again, $\sigma_{\text {hold }}$ ) was applied during a certain dwell time, $\Delta t_{\text {anneal }}$, to ensure complete recrystallisation before starting the creep test itself at a stress level, $\sigma_{\text {creep }}$, similar to those used for creep tests (Fig. 1b). A few "doublehit" tests of the type shown in Fig. 1d were also carried out. Here, the pre-deformation stage was repeated after a given dwell time, again denoted as $\Delta t_{\text {anneal }}$. True axial strains were calculated from diametral measurements except for those corresponding to double-hit tests, which were derived from the anvil displacements. Unless otherwise stated, the true compressive stresses presented in this work were obtained by assuming that specimens deformed uniformly during the pre-deformation and creep stages.

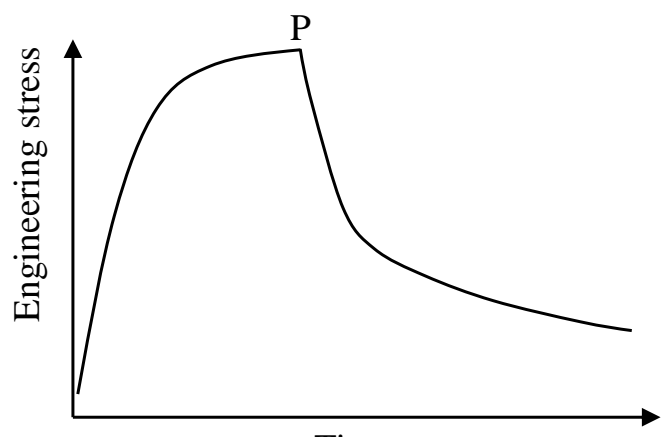

(a)

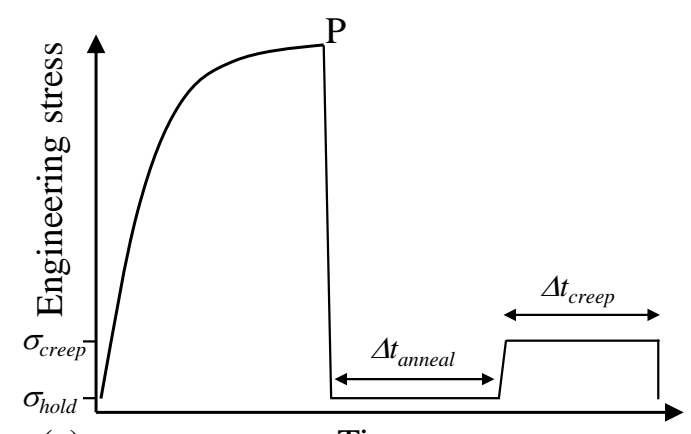

(c)
Time

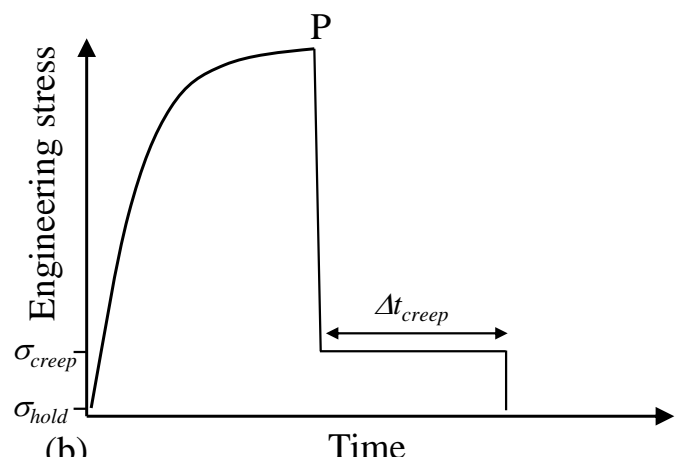

(b)

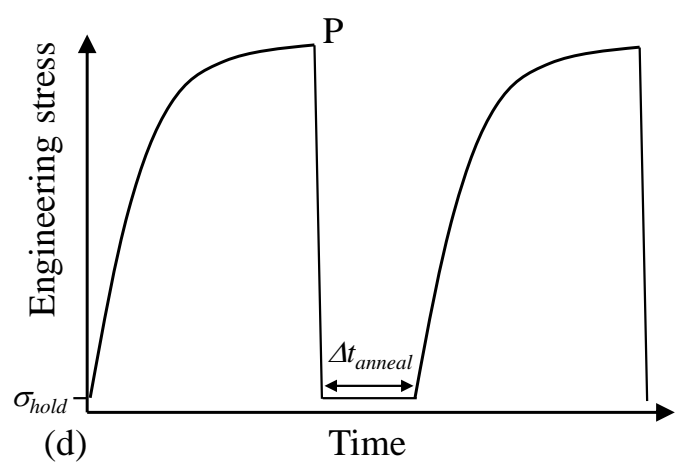

(d)
Time

Fig. 1. Schematic stress vs. time plots for (a) stress relaxation, (b) creep, (c) delayed creep and (d) double-hit tests. Point $\mathrm{P}$ denotes the end of the pre-deformation step. The duration of the unloading stage right after point $\mathrm{P}$ in $(\mathrm{b}-\mathrm{d})$ is 2 seconds. 
The recrystallisation kinetics under various stress levels was first investigated using stress relaxation tests (Fig. 1a) as in $[44,45]$. In order to confirm the assessed recrystallisation kinetics that could be affected by e.g. thermal gradients along the loading axis [46], the softening kinetics was then quantified from double-hit tests after different annealing times ( $\Delta t_{\text {anneal }}$ in Fig. $\left.1 \mathrm{~d}\right)$, and compared with the stress relaxation test results. To investigate the microstructural evolution during recrystallisation and further confirm the recrystallisation kinetics, some creep tests were interrupted by water quenching after various lengths of creep times $\left(\Delta t_{\text {creep }}\right.$ in Fig. 1b). The microstructure of these specimens was examined using EBSD and transmission electron microscopy (TEM).

The impact of recrystallisation on viscoplastic deformation was determined from the creep tests on the material hot-worked up to point P (Fig. 1b). The viscoplastic behaviour of the fully recrystallised material was investigated using the delayed creep tests, Fig. 1c. From the recrystallisation kinetics results, $\Delta t_{\text {anneal }}$ was set to $20 \mathrm{~min}$ to ensure complete recrystallisation before applying the creep stress. A medium-level engineering stress, $\sigma_{\text {creep }}$ of $47 \mathrm{MPa}$ was chosen here.

The EBSD measurements were performed at the mid-radius and the mid-height of the specimens' longitudinal sections using an EDAX TSL-OIM system attached to a Nova NanoSEM 450 scanning electron microscope operated at $20 \mathrm{kV}$. The specimens were polished down to $1 \mu \mathrm{m}$ using diamond pastes followed by a colloidal silica finish, leading to $>99 \%$ of indexed pixels. The EBSD parameters were: tilt angle $70^{\circ}$, working distance $10-19 \mathrm{~mm}$, step size 0.5 to $1 \mu \mathrm{m}$, magnification 120 to 400 , and map size $200 \times 200 \mu \mathrm{m}^{2}$ (for $0.5 \mu \mathrm{m}$ step size in order to detect the finest possible recrystallised grains) and $810 \times 1200 \mu \mathrm{m}^{2}$ (for $1 \mu \mathrm{m}$ step size, in order to quantify the recrystallised fraction over a larger area). Noise reduction by grain dilation, with a grain tolerance of $5^{\circ}$ and a minimum grain size of 2 pixels, was applied before analysing the EBSD data. The TEM observations were performed using a FEI Tecnai G2 20 S-twin system. Thin foils taken perpendicular to the compressive axis were electrolytically thinned down in a solution of $95 \%$ acetic acid and $5 \%$ perchloric acid.

\section{Experimental Results}

\subsection{Recrystallisation kinetics and associated microstructural evolution}

\subsubsection{Recrystallisation kinetics estimated from stress relaxation tests}

The flow curves obtained during pre-deformation were close to those reported by [34], yet with a slightly lower flow stress, possibly due to a difference in lubrication conditions and strain measurement method. The effects of pre-deformation strain rate and temperature on stress relaxation 
are shown in Figs 2a and 2b, respectively. In Fig. 2a, the stress relaxation curve after pre-deformation at $850^{\circ} \mathrm{C}$ and $0.01 \mathrm{~s}^{-1}$ shows three distinct stages, with the rate of stress decrease being greater in Stage II than in Stages I and III. These observations are consistent with reported stress relaxation behaviour of austenite in C-Mn steels under similar loading conditions [44, 45]. This trend was less clearly observed at higher strain rates $\left(0.1\right.$ and $\left.0.44 \mathrm{~s}^{-1}\right)$. The measured temperature effect on stress relaxation is shown in Fig. $2 b$, where rapid stress drops can be seen. At temperatures between 850 and $950^{\circ} \mathrm{C}$, the stress drop (Stage II) begins two seconds after the end of pre-deformation and stresses are almost completely relaxed within $400 \mathrm{~s}$ at $850^{\circ} \mathrm{C}$, within $100 \mathrm{~s}$ at $900^{\circ} \mathrm{C}$, and within $10 \mathrm{~s}$ at $950^{\circ} \mathrm{C}$. At $1050^{\circ} \mathrm{C}$, the stress decreases rather rapidly immediately after the end of the pre-deformation stage, resulting in no obvious transition between Stage I and Stage II. Such rapid stress relaxation at $1050^{\circ} \mathrm{C}$ can be explained by the occurrence of meta-dynamic recrystallisation [5, 47, 48], which begins immediately after pre-deformation, without exhibiting any incubation period.
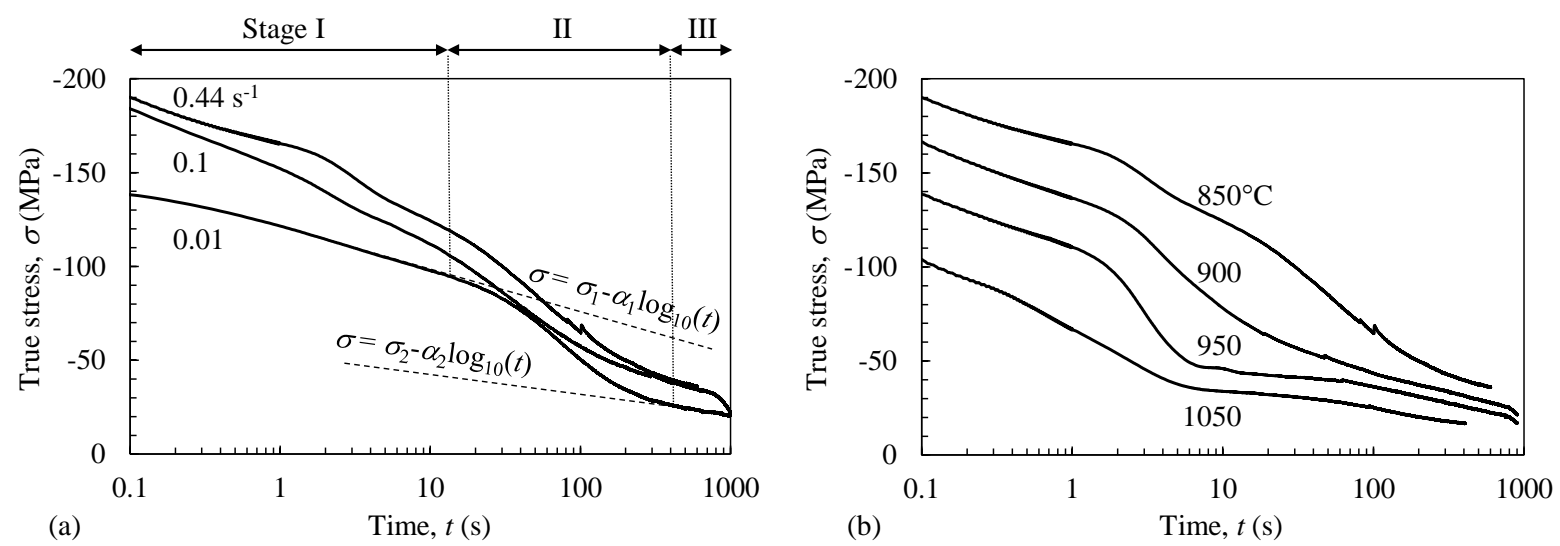

Fig. 2. Stress relaxation curves for $\mathrm{Fe}-36 \% \mathrm{Ni}$ alloy after $30 \%$ hot compression (a) at $850^{\circ} \mathrm{C}$ and various pre-deformation strain rates, and (b) at different temperatures and a pre-deformation strain rate of $0.44 \mathrm{~s}^{-1}$. The dashed lines in (a) are linear extrapolations of the experimental data for one particular case.

Karjalainen [45] suggested that Stages I and III correspond to the stress relaxation of hot worked and recrystallised materials, respectively. Each of these stages can be well described by the straight dashed lines shown in Fig. 2a, a linear extrapolation of Stages I and III data. It is worth noting that Stage II involves a material with two populations of grains (work-hardened ones and recrystallised ones), and that the rapid stress drop is attributed to an increase in the volume fraction of recrystallised grains. Using a rule of mixtures, the stress relaxation in Stage II can be phenomenologically expressed as a function of time, $t$, as [45]

$\sigma=(1-X)\left(\sigma_{1}-\alpha_{1} \log _{10} t\right)+X\left(\sigma_{2}-\alpha_{2} \log _{10} t\right)$

where, $X$, is the estimated volume fraction of recrystallised grains, and subscripts 1 and 2 refer to the work-hardened and recrystallised grains, respectively. An expression for $X$ as a function of time can be obtained from eq. (1) as follows [45], 
$X=\frac{\left[\left(\sigma_{1}-\alpha_{1} \log _{10} t\right)-\sigma\right]}{\left[\left(\sigma_{1}-\alpha_{1} \log _{10} t\right)-\left(\sigma_{2}-\alpha_{2} \log _{10} t\right)\right]}$

The value of $X$ can be readily estimated as a function of time from eq. (2) using the experimental parameters obtained from the data in Fig. 2a. Two out of the three different testing conditions (i.e., temperature and pre-deformation strain rate) shown in Fig. 3 were selected to compare the estimates of $X$ from Eq. 2 with either direct measurement from microstructural observations or fractional softening estimates from double hit tests. Only Condition $\mathrm{A}\left(850^{\circ} \mathrm{C}\right.$ and $\left.0.01 \mathrm{~s}^{-1}\right)$ leads to slow recrystallisation kinetics, which enables microstructural observations to be carried out after interrupted creep tests. Condition $\mathrm{B}\left(950^{\circ} \mathrm{C}\right.$ and $\left.0.44 \mathrm{~s}^{-1}\right)$ is closer to those at the beginning of hot finishing rolling processes where an acceleration of creep strains by recrystallisation phenomena is expected; the rapid recrystallisation kinetics allowed double hit tests to be performed at $950^{\circ} \mathrm{C}$ while still avoiding oxidation-related issues. Condition $\mathrm{C}\left(1050^{\circ} \mathrm{C}\right.$ and $\left.0.44 \mathrm{~s}^{-1}\right)$ is even closer to the hot finishing rolling process but is associated to very rapid recrystallisation kinetics, that could only be estimated using the stress relaxation tests.

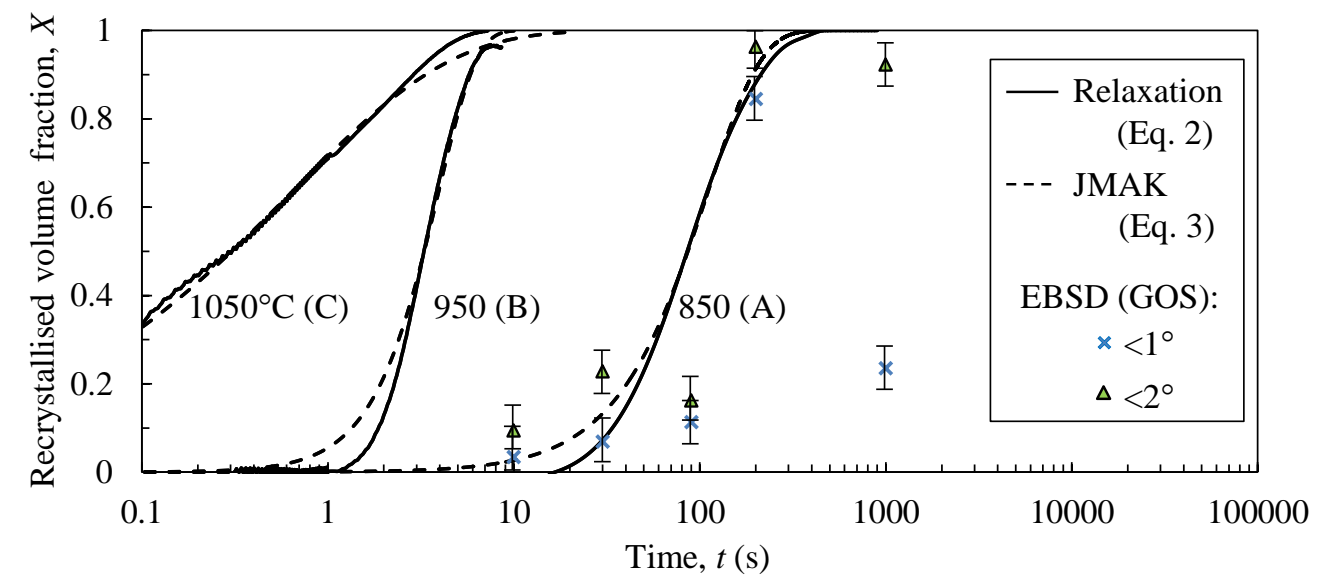

Fig. 3. A comparison between the volume fraction of recrystallised material vs. time, calculated from eq. (2) and from the JMAK relationship (eq. (3)), and measured by EBSD after interrupted creep tests

Furthermore, since the three recrystallisation kinetics curves (continuous lines in Fig. 3) exhibit typical sigmoidal shapes, they were mathematically described as in [45] by the Johnson-Mehl-AvramiKolmogorov relationship (JMAK) [49-51] as follows,

$X=1-\exp \left(-A\left(\frac{t}{t_{50 p c t}}\right)^{n}\right)$

In eq. (3), $A=\ln (2) \approx 0.693, n$ is a material coefficient, and $t_{50 p c t}$ (also a material coefficient) is the holding time for $50 \%$ recrystallisation, adjusted to $86 \mathrm{~s}$ and $3.2 \mathrm{~s}$ for the Conditions $\mathrm{A}$ and $\mathrm{B}$, respectively. Note that since the recrystallisation kinetics not only depends strongly on temperature but also on the strain rate applied during the pre-deformation stage (as in e.g. [45]), the material parameters in eq. (3) were adjusted independently for each of the Conditions A, B and C. Calibrated values of exponent $n$ for Conditions $\mathrm{A}(n=1.5)$ and $\mathrm{B}(n=2.1)$ are consistent with those commonly reported for static recrystallisation $[1,45,52]$, especially after high amounts of pre-deformation that 
could involve heterogeneous deformations [53] and low associated Avrami exponents [54]. For Condition $\mathrm{C}$, the value of $n=0.5$ was lower than for the other conditions due to the fast stress relaxation that precluded a complete determination of the recrystallisation kinetics. Fig. 3 shows satisfactory agreement between relaxation results and description from eq. (3).

\subsubsection{Microstructural information from interrupted creep tests}

The microstructure of the recrystallising material was investigated through interrupted creep tests using Condition A, involving relatively slow recrystallisation kinetics. After pre-deformation, creep tests were carried out at $20 \mathrm{MPa}$ for $\Delta t_{\text {creep }}=10,30,90,200$ and $1000 \mathrm{~s}$ and then interrupted by water quenching. Their microstructures were analysed through Grain Orientation Spread (GOS) maps obtained from EBSD, defined as the average difference in the orientations between any pixel of a given grain and the average orientation of that grain. Freshly recrystallised grains exhibiting little internal misorientations exhibit lower GOS values (i.e., typically the blue grains in Fig. 4). In contrast, deformed grains were associated with higher GOS values. It can be seen in Fig. 4 that recrystallised grains are surrounded by deformed grains. This suggests that recrystallisation occurred by nucleation and growth of new grains at the boundaries of work-hardened ones only. These results agree with those reported by Richardson [20] on $\mathrm{Ni}$ at $1000^{\circ} \mathrm{C}$. Moreover, many recrystallised grains found in EBSD maps are relatively large $(\sim 20 \mu \mathrm{m})$, while the minimum grain size that could be detected using these maps ranged between 1 and $2 \mu \mathrm{m}$, depending on the step size and noise reduction procedure. Consequently, right after the onset of recrystallisation, rather fast growth of newly recrystallised grains was found to have already started. The GOS histograms (Fig. 4c) show a majority of grains bearing high internal misorientations for $\Delta t_{\text {creep }}$ up to $90 \mathrm{~s}$. In the specimen that crept for $90 \mathrm{~s}$, a bimodal distribution is observed (see the arrow in Fig. 4c), indicating significant recrystallisation after that creep time. Consequently, the average GOS of non-recrystallised grains is higher than that for the specimen that crept for $\Delta t_{\text {creep }}=30 \mathrm{~s}$ only, which contains a much lower fraction of recrystallised grains. After $\Delta t_{\text {creep }}=200 \mathrm{~s}$, a majority of grains are recrystallised; here, the GOS values of recrystallised grains are higher for $\Delta t_{\text {creep }}=1000 \mathrm{~s}$ than for $\Delta t_{\text {creep }}=200 \mathrm{~s}$, due to additional creep strain (less than 0.04 , in that case).

To quantitatively distinguish recrystallised grains from work-hardened ones, an identification of a critical GOS value is necessary. The bimodal distribution found for $\Delta t_{\text {creep }}=90 \mathrm{~s}$ (Fig. 4c) suggests that newly recrystallised grains have a GOS value lower than $1^{\circ}$, at least after small amounts of creep strain (e.g. less than 0.01), as shown by blue grains in Figs $4 \mathrm{a}$ and $4 \mathrm{~b}$. A threshold value of $2^{\circ}$ was also tested, as first recrystallised grains further experienced some creep deformation. The area fractions of recrystallised grains are reported in Fig. 3 for the two criteria. Due to the equiaxed grain morphology, the recrystallisation volume fraction was assumed to be equal to the measured area fraction. For $\Delta t_{c r e e p}$ 
$=90 \mathrm{~s}$ (Fig. 4b), the area fraction of the grains with low GOS values is between 0.1 and 0.2 , whereas it approaches 0.9 for $\Delta t_{\text {creep }}=200 \mathrm{~s}$. A criterion of $1^{\circ}$ seems relevant at the beginning of the creep tests, whereas most recrystallised grains had a GOS value higher than $1^{\circ}$ after creeping for $1000 \mathrm{~s}$, due to the creep deformation itself.
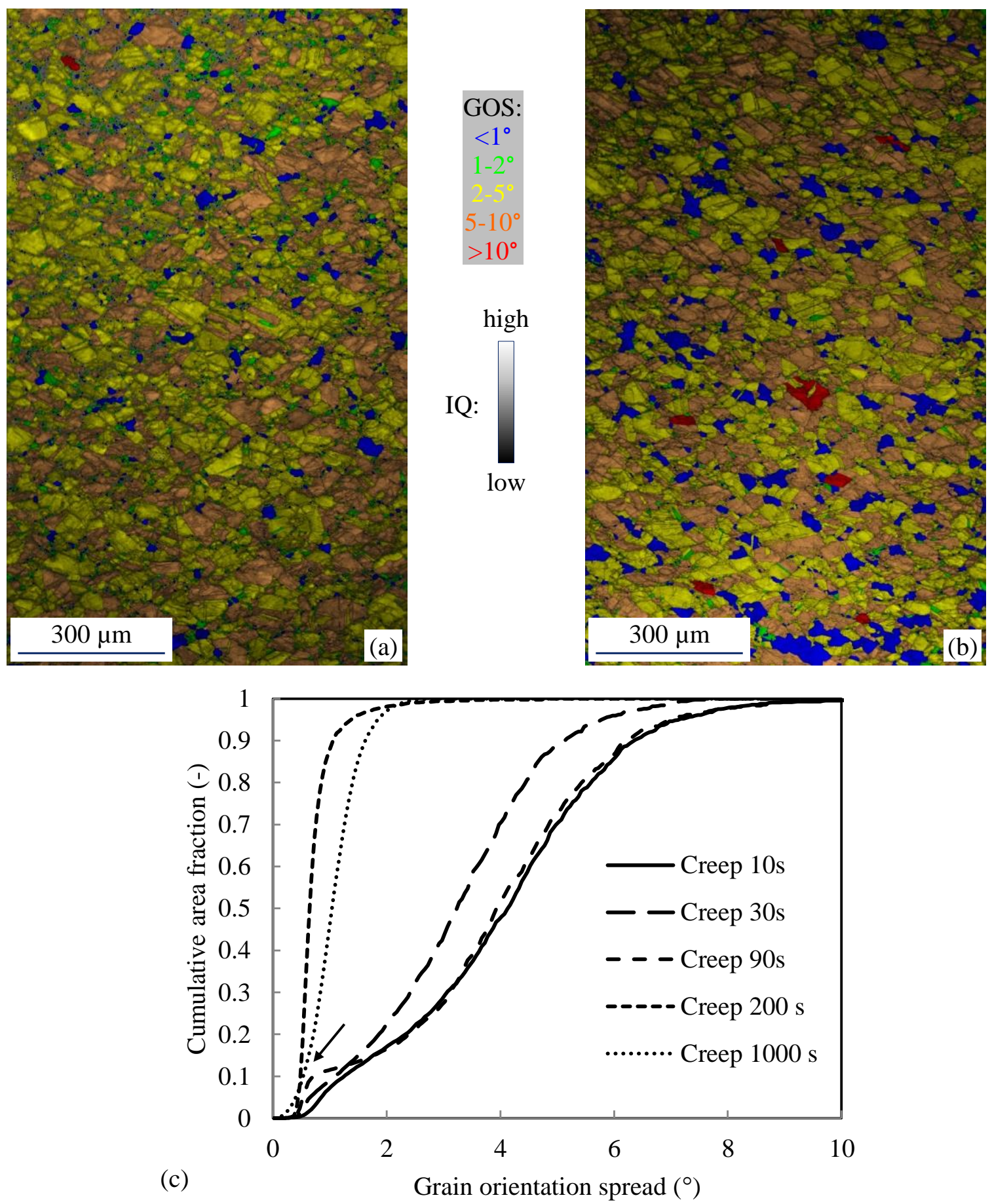

Fig. 4. Microstructural information of partially recrystallised samples at $850^{\circ} \mathrm{C}$ and $20 \mathrm{MPa}(\mathrm{a}, \mathrm{b})$ combined image quality (IQ) + GOS maps after 30 and $90 \mathrm{sec}$. creep tests, respectively (the compression axis is along the vertical direction) and (c) GOS histograms for the different creep times. The arrow in this figure indicates the small fraction of recrystallised grains found in the bimodal GOS distribution after $90 \mathrm{~s}$ creep. 
Finer scale information was obtained through TEM for the same crept specimens. The dislocation density of unrecrystallised grains appeared still high. Only few very small grains were observed for $\Delta t_{\text {creep }}=30 \mathrm{~s}$ and none for $\Delta t_{\text {creep }}=90 \mathrm{~s}$, suggesting that after $90 \mathrm{~s}$, grains had already grown past the nucleation stage. Figure 5 shows that, for $\Delta t_{\text {creep }}=30 \mathrm{~s}$, a nucleus was formed at a grain boundary junction, which confirms that recrystallisation started from the boundaries of deformed grains. Even if available observations do not constitute conclusive evidence about the underlying recrystallisation mechanism (e.g., by grain boundary bulging or by a fully discontinuous nucleation event), no continuous necklace structure could be observed with the TEM. For instance, small recrystallised grains, such as the bright ones at the centre of the image, appeared isolated from other similar recrystallised grains. This was also the case for newly recrystallised grains (GOS $<1^{\circ}$ ) observed in the EBSD maps of Fig. 4. As a whole, newly recrystallised grains may be considered as isolated from each other and embedded in a harder, work-hardened matrix.

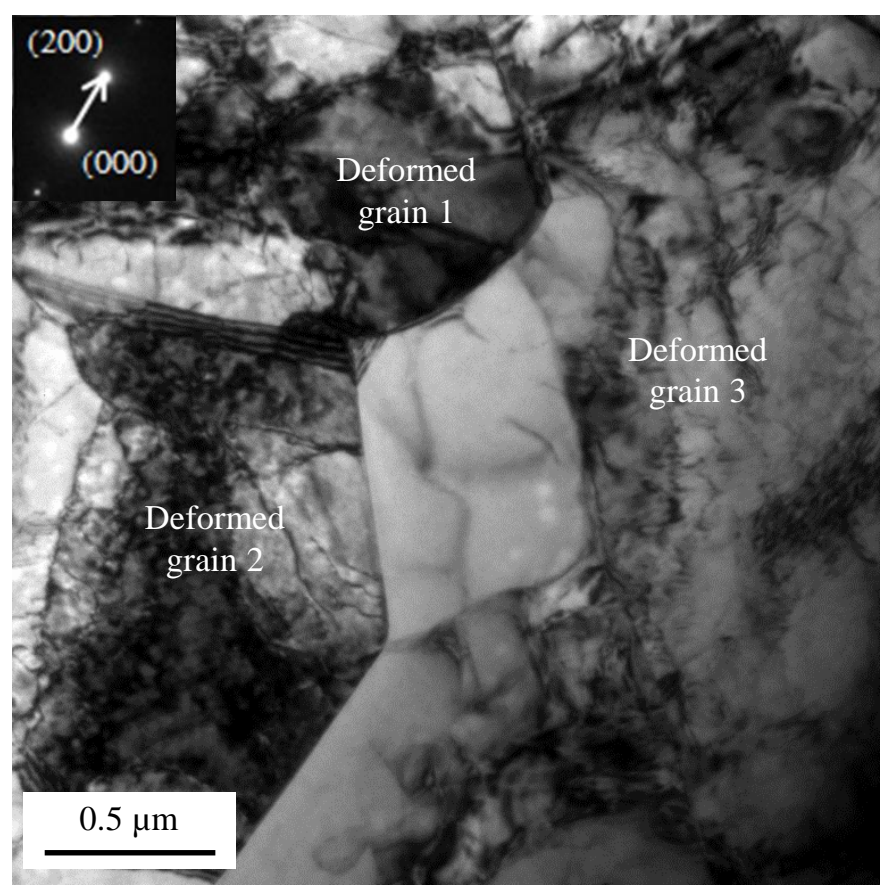

Fig. 5. TEM bright-field micrograph of the specimen crept for $30 \mathrm{~s}$, showing an almost dislocationfree nucleus (bright grain in the central part of the image) and surrounding grains with high dislocation densities

\subsubsection{Softening fractions measured from double-hit tests}

The flow curves obtained from double-hit compression tests of the type illustrated in Fig. $1 \mathrm{~d}$ at $950^{\circ} \mathrm{C}$ with two different dwell times (4 s and $12 \mathrm{~s}$ ) are shown in Fig. 6. To facilitate a comparison, the true flow stress vs. strain curve obtained from the second deformation stage ("second hit") was recalculated based on the pre-deformed geometry, and superimposed to that obtained from the pre-deformation stage ("first hit"). 


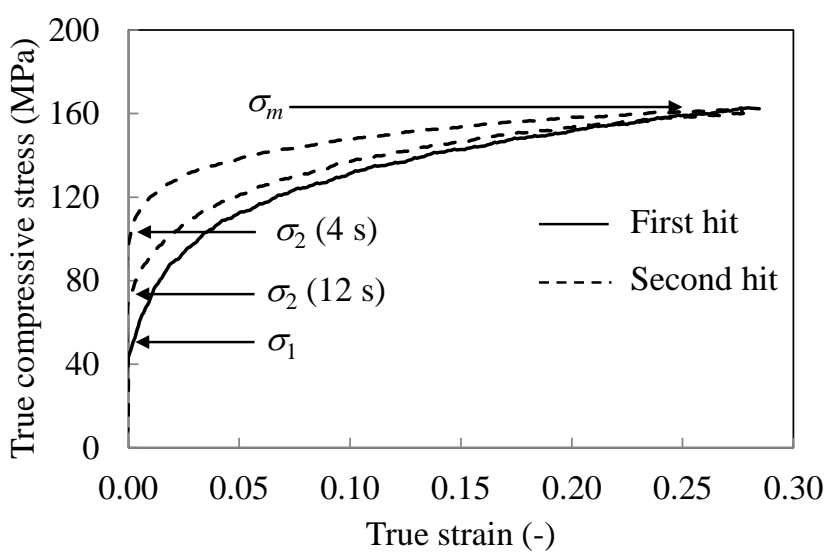

Fig. 6. Double-hit compression flow curves obtained at $950^{\circ} \mathrm{C}$ and with a strain rate of $0.44 \mathrm{~s}^{-1}$

The softening fractions, $S_{f}$, were determined according to the following relation,

$S_{f}=\frac{\sigma_{m}-\sigma_{2}}{\sigma_{m}-\sigma_{1}}$

where, $\sigma_{m}$, is the flow stress at the end of the first hit, and $\sigma_{1}$ and $\sigma_{2}$ are the $0.2 \%$ offset flow stresses for the first and the second hits, respectively. The values of the softening fractions for $\Delta t_{\text {anneal }}=4 \mathrm{~s}$ and $\Delta t_{\text {anneal }}=12 \mathrm{~s}$ were found to be 0.50 and 0.77 , respectively. These findings suggest a significant extent of recrystallisation during the first twelve seconds. However, the recrystallisation fractions cannot be directly obtained from these measurements because recovery also contributes to softening. For comparison, the recrystallisation kinetics at $950^{\circ} \mathrm{C}$, estimated from relaxation tests (eq. (2)) that exclude the contribution from recovery, yielded somewhat higher values of 0.7 and 1 after relaxation for 4 and $12 \mathrm{~s}$, respectively.

\subsubsection{Comparison between microstructural evolution derived from stress relaxation, interrupted creep and double-hit tests}

Estimates of recrystallised fractions obtained at $850^{\circ} \mathrm{C}$ with Condition A from stress relaxation and from interrupted creep tests are compared in Fig. 3. The applied stress levels are around $20 \mathrm{MPa}$ for interrupted creep and decreasing from about $150 \mathrm{MPa}$ down to about $50 \mathrm{MPa}$ during stress relaxation. Despite this difference in stress levels, Fig. 3 shows fair agreement between the EBSD measured kinetics data and the calculated trends using eqns. (2) and (3), even if the recrystallisation kinetics is overestimated by the stress relaxation method, at least at the beginning. The GOS criterion of $1^{\circ}$ is rather insensitive to recovery of unrecrystallised grains, whereas the estimate of $X$ by stress relaxation assumes that recovery of recrystallised grains, as well as recovery of non-recrystallised grains depend on stress level (as in [53]) but do not depend on the fraction of recrystallised grains itself (and thus, on the stress and strain partition between recrystallised and non-recrystallised grains). This strong assumption could affect the accuracy of estimates of $X$ from stress relaxation tests. 
On the other hand, double hit tests (in which fractional softening includes a contribution from recovery) yielded values of fractional softening lower than estimates of $X$ at $950^{\circ} \mathrm{C}$. The same observation was reported by [53] in a Fe-C-Mn steel during hot compression tests in the fully austenitic domain. As the stress experienced by the specimens during relaxation in Condition B (in the present work, from $110 \mathrm{MPa}$ down to about $50 \mathrm{MPa}$ ) was higher than that used to hold the specimens in the interpass time during the double hit tests (a few MPa in the present case), a slight acceleration of recrystallisation due to the applied stress could still be present. This point is addressed in the Discussion section below. Nevertheless, both types of tests show that the material fully recrystallises during the first $10-20$ seconds after pre-deformation in Condition B. Moreover, the stress levels used in the relaxation tests are of the same order of magnitude as those used in the creep tests, at least at $950^{\circ} \mathrm{C}$ (Condition $\left.\mathrm{B}\right)$.

In order to compare the recrystallisation kinetics to the evolution of viscoplastic behaviour during creep, the JMAK equation will be used in the following, despite its above mentioned limitations, as it provides a continuous estimate of the recrystallised fractions with time.

\subsection{Creep behaviour}

\subsubsection{Recrystallisation-assisted creep}

Recrystallisation-assisted creep behaviour was studied at various creep temperatures. The evolution of strain rate with creep time under the different pre-deformation conditions is shown in Fig. 7 together with the previously obtained recrystallisation volume fractions. Note that the time scales for the curves of Fig. 7 are consistent with each other since they start from the end of the pre-deformation stage. At $1050^{\circ} \mathrm{C}$, extensive recrystallisation had already occurred during the 2-second-unloading stage, leading to the high fraction of recrystallised grains during the creep part of the test (Fig. 7c). These results reveal certain common features: the strain rates are relatively low at the beginning of the creep test due to the high dislocation density in work-hardened grains. Then, increases in strain rate are observed in most cases followed by a stage of decreasing ones. Note that for clarity, some data at times $(<1-6 \mathrm{~s})$ has not been included due to the high measured noise. It can be seen that during recrystallisation, indicated by the period where the recrystallisation volume fraction $(X)$ evolves with time in Figs. 7, the strain rate generally increases except at the very end of the recrystallisation where it starts to decrease. Note also that during the $\sim 10 \mathrm{~s}$ incubation time at $850^{\circ} \mathrm{C}$, slight increases in strain rate were also observed. 

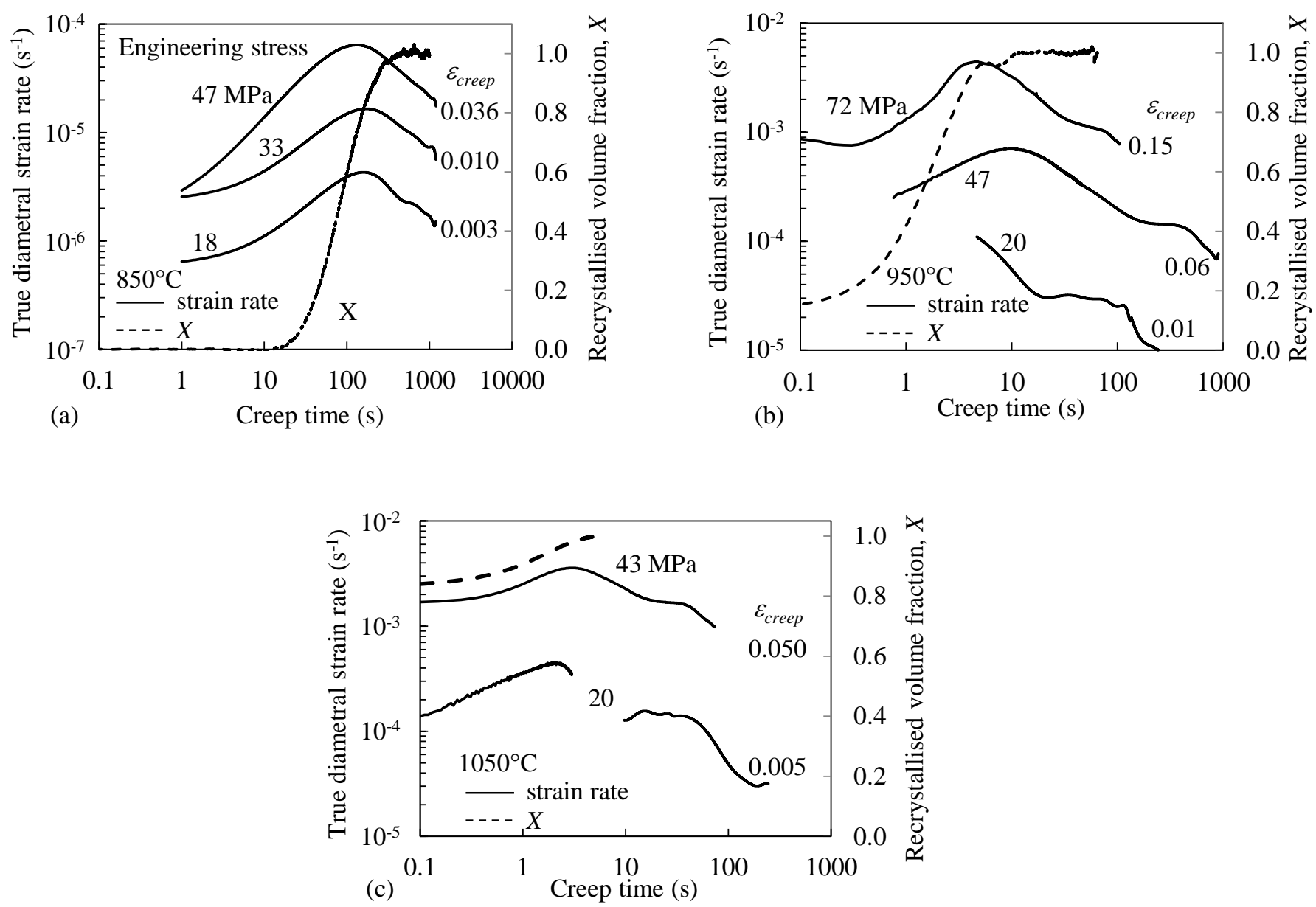

Fig. 7. Measured recrystallisation-assisted viscoplastic deformation at mid-height of the specimen during creep tests (thermomechanical cycle of Fig. 1b) at (a) $850^{\circ} \mathrm{C}$ (Condition A), (b) $950^{\circ} \mathrm{C}$ (Condition B), and (c) $1050^{\circ} \mathrm{C}$ (Condition C) superimposed to the recrystallisation kinetics curve determined from eq. (2) but taking the 2-second-unloading time into account. Engineering (compressive) stresses $\sigma_{\text {creep }}$ and final amounts of creep strain, $\varepsilon_{\text {creep }}$, are indicated next to each curve.

In order to investigate the stress dependence of strain rates, some representative experimental data during and after the recrystallisation shown in Fig. 7 were extracted and are presented in Figs 8a and $8 \mathrm{~b}$ as a function of the true compressive stress (i.e., the applied load divided by the instantaneous midheight section). The results obtained at $950^{\circ} \mathrm{C}$ under an engineering stress of $47 \mathrm{MPa}$ are shown in Fig. 8a. Here, the true stress decreases during the creep test as a result of the gradual increase in specimen cross-section during compression, so that the curve should be read from right to left. The first three data points in Fig. 8a correspond to the viscoplastic behaviour of the recrystallising material, that is, during recrystallisation, and the other ones describe the creep behaviour of the material after recrystallisation. During recrystallisation, the true strain rates increase rapidly until the material is fully recrystallised, followed by a decrease until the end of the creep test. In the recrystallised region of Fig. 8a, the decreasing strain rates can be approximately assumed to exhibit two stages: one involving a fast decreasing strain rate, and a second one characterised by a lower constant $\log$ strain rate - log stress slope (slope 2 in Fig.8a). 

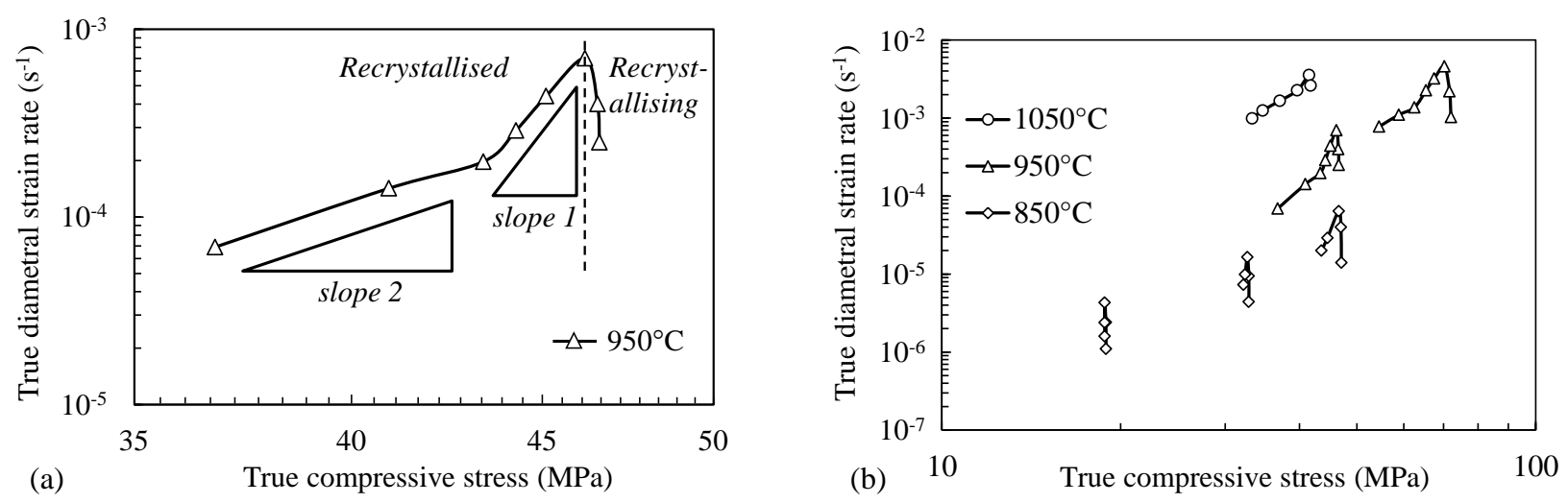

Fig. 8. Measured true compressive stresses - true diametrical strain rates in the specimen mid-section (a) at $950^{\circ} \mathrm{C}$ under an applied engineering stress of $47 \mathrm{MPa}$, and (b) at temperatures ranging from $850 \sim 1050^{\circ} \mathrm{C}$ under various applied stresses. Curves should be read from right to left.

Similar results were obtained at all test temperatures under engineering stress ranging from 18 to 72 MPa (Fig. 8b). At $850^{\circ} \mathrm{C}$, only the increasing strain rates during recrystallisation and the first stage after full recrystallisation (slope 1) were readily identified; note that the lower the applied stress or test temperature, the lower the total amount of creep strain, $\varepsilon_{\text {creep }}$ (see Fig. 7) and the smaller the variation in true compressive stress during the creep part of the test. The tests had to be stopped before attaining the second strain rate stage (slope 2) after full recrystallisation, to avoid excessive specimen oxidation. At $950^{\circ} \mathrm{C}$, all stages can be identified, and at $1050^{\circ} \mathrm{C}$ the creep data were only associated with the end of recrystallisation, as shown in Fig. 7c, leading to a limited increase in strain rate, followed by two successive decreasing strain rate stages.

From the results reported in Fig. 8, the second creep rate stage of the recrystallised material at $950^{\circ} \mathrm{C}$ and $1050^{\circ} \mathrm{C}$ can be attributed to the classical power-law creep regime. Assuming a power-law strain rate dependence on applied stress, then the data from Fig. 8 gives a creep exponent of $\sim 5$. This value is rather close to the steady state creep exponent of pure $\mathrm{Ni}(\sim 4.6)[55]$ in the high-temperature regime. This result suggests that in the investigated conditions, the steady state creep behaviour of recrystallised $\mathrm{Fe}-36 \% \mathrm{Ni}$ is dominated by dislocation creep, which is consistent with the slight internal misorientation of recrystallised grains after some viscoplastic deformation as detected with EBSD using the GOS distribution (see Fig. 4). The steady state creep data obtained under true stresses of $36-$ $40 \mathrm{MPa}$ at $950^{\circ} \mathrm{C}$ and $1050^{\circ} \mathrm{C}$ were used to identify the activation energy of viscoplastic deformation. The resulting value $(300 \pm 15 \mathrm{~kJ} / \mathrm{mol})$ is close to that of the lattice diffusion activation energy of pure nickel $(284 \mathrm{~kJ} / \mathrm{mol})$ and of 316-type austenitic stainless steels $(280 \mathrm{~kJ} / \mathrm{mol})$ [55], and far from usual values of grain boundary diffusion activation energy $(115 \mathrm{~kJ} / \mathrm{mol}$ for nickel and $167 \mathrm{~kJ} / \mathrm{mol}$ for 316 stainless steel) [55]). 
Based on the above observations, it is also plausible that the first stage of the decreasing strain rate region be associated with primary creep of the recrystallised material, in agreement with the assumption proposed by Gifkins [18]. The validity of this assumption was confirmed with the results from delayed creep tests performed on the fully recrystallised material, as reported in the next section.

\subsubsection{Creep of recrystallised materials}

The creep behaviour of annealed, fully recrystallised specimens was investigated at $850^{\circ} \mathrm{C}$ and $950^{\circ} \mathrm{C}$ using delayed creep tests (see Fig. 1c) with a stress of $47 \mathrm{MPa}$. The corresponding strain rates are compared in Fig. 9 to those obtained from creep tests of recrystallising specimens (see Fig. 1b) under the same loading conditions. The results reveal that the recrystallised material, which contains a very low dislocation density, exhibits a primary creep regime with a decreasing strain rate due to an increase in dislocation density. In contrast, the recrystallising material reveals an initially increasing strain rate at both temperatures, before attaining a peak. These results show, for the first time, that such acceleration of the deformation during recrystallisation is undoubtedly due to recrystallisation-related mechanisms. It is also worth noting that (i) the maximal values of strain rate during the creep tests of the recrystallising material are similar to the strain rates of the recrystallised specimens at the same (creep) times, and that (ii) the subsequent evolution of the creep rates in the two different types of tests is similar.

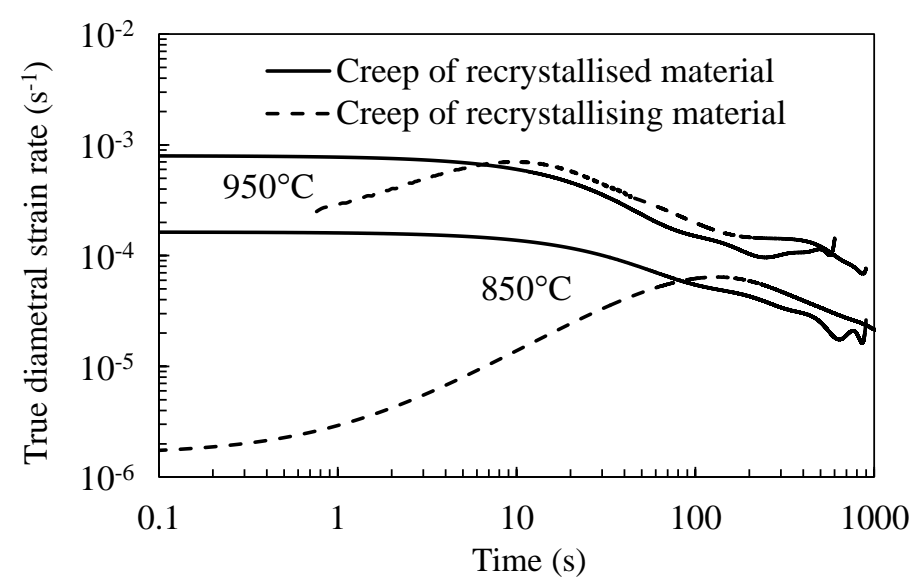

Fig. 9. Evolution of strain rate with creep time during creep tests of recrystallising specimens (i.e. see Fig. 1b) and delayed creep tests (i.e. see Fig. 1c) (labelled as "creep of recrystallised material") under the same engineering stress of $47 \mathrm{MPa}$

\section{Discussion}

\subsection{Effect of stress on recrystallisation kinetics}

It was reported that an applied stress can drastically change the recrystallisation kinetics of coldworked $\mathrm{Al}-2 \% \mathrm{Mg}$ and copper $[56,57]$. On the other hand, only limited effect of stress on static recrystallisation was reported in isothermal conditions, namely, after hot deformation of austenite followed by either stress relaxation or double hit tests [53, 58]. Džubinský et al. [53] attributed the 
faster recrystallisation kinetics found from stress relaxation tests to an accelerating effect of stress on recovery; no metallographic observation could be made, due to austenite decomposition after the end of the test. Such an effect of applied stress on the static recrystallisation kinetics was only reported by Perttula et al. [58] for fine-grained $(<30 \mu \mathrm{m})$ microstructures or low levels of strain (up to 0.15). In the present case, the amount of pre-strain was close to the upper values reported by Perttula et al. [58] and the austenite grain size (here, $50 \mu \mathrm{m}$ in average) was in-between "fine-grained" and "coarse-grained" characteristics reported in their paper. As a consequence, the sensitivity of the recrystallisation kinetics to the applied stress cannot be quantitatively compared with the work from [58] but the present findings (some possible acceleration of recrystallisation by the higher values of stress applied during relaxation tests) are consistent with their results. In addition, this limited stress effect on the recrystallisation kinetics can also be revealed from the creep test results shown in Fig. 7. For a given pre-deformation condition, the strain rate peaks can be found to occur after similar amounts of time irrespective of the value of applied stress during the creep stage. All this evidence suggests that the effect of constant applied stress on the recrystallisation behaviour of $\mathrm{Fe}-36 \% \mathrm{Ni}$ is a second-order one for the conditions investigated here, in agreement with the phenomenological description of recrystallisation kinetics by the JMAK relation, eq. (3).

\subsection{Mechanisms which contribute to an acceleration of the deformation during recrystallisation}

As previously shown, recrystallisation-assisted viscoplastic deformation is strongly coupled to the microstructural evolution, which involves the generation of nuclei, grain growth, and the coexistence of two distinct grain populations. The measured deformation acceleration which accompanies recrystallisation could be attributed to different mechanisms, three of which are discussed next.

\subsubsection{Resistance of unrecrystallised grains to viscoplastic deformation}

In the dislocation creep regime, the back stress introduced by existing dislocations (e.g. from cold work) generally increases the resistance to viscoplastic deformation, in the absence of any change in loading path. Even though several publications have discussed this phenomenon after cold working in materials other than Invar, the effect of hot work on creep strength has not been addressed yet. For instance, in austenitic steels (e.g., [59-62]) as well as in nickel base superalloys (e.g., [63]), controlled cold working of a solution-annealed microstructure was found to increase the creep strength by allowing fine second phase precipitates to form during creep and to stabilize the dislocation structure against recovery. In the present solid-solution material, the introduction of a high dislocation density (as illustrated in Fig. 5) by hot deformation increased the creep strength up to the onset of recrystallisation. Interactions between dislocations inherited from the pre-deformation stage and mobile dislocations during creep could be at the origin of the higher creep strength of unrecrystallised grains. 


\subsubsection{Diffusional flow along grain boundaries}

It is known that the rate of diffusional flow along grain boundaries [64] may be significant in microstructures with very fine grains such as newly formed nuclei. It was reported in [25], that diffusional flow along nuclei boundaries could result in an acceleration of the deformation during recrystallisation, yet no microstructural evidence was presented. However, microstructural investigations from this work suggest that such diffusional flow is very limited. For instance, in Figure 5, every small grain was found to be surrounded by unrecrystallised, harder ones. Moreover, no continuous necklace of very small grains was found in the TEM. Furthermore, in the EBSD maps of Fig. 4 , a significant fraction of recrystallised grains $\left(\mathrm{GOS}<1^{\circ}\right)$ was found to have already reached a rather large size (typically, $20 \mu \mathrm{m}$ ) well before the completion of recrystallisation during the creep test itself. As a consequence, deformation of small recrystallised grains by diffusional flow along grain boundaries is not expected to significantly contribute to an acceleration of the macroscopic strain.

\subsubsection{Primary creep deformation of recrystallised grains}

Another possible origin of strain acceleration during recrystallisation could stem from the increasing contribution of the viscoplastic deformation of recrystallised grains themselves. As shown in Fig. 9, fully recrystallised specimens exhibited a primary creep regime with initial strain rates close to the strain rate peaks observed in the creep tests. These results, together with the high stress exponents in fully recrystallised material (Fig. 8), suggest that during recrystallisation under stress, newly formed grains might exhibit a primary creep regime and that their contribution to the overall deformation could be significant. In order to quantify this possible contribution, a simple, phenomenological model was developed and it is described next. The specific details about the model formulation are given in the appendix.

At any (creep) time, the material is assumed to be composed of two populations of grains, namely, unrecrystallised and recrystallised ones. As a first approximation, the recrystallised and unrecrystallised grains are considered to deform under the same engineering stress (Kelvin-Sachs assumption of uniform stress), and the average strain rate is assumed to depend on the volume fraction and flow behaviour of each of the two grain populations. The flow behaviour of recrystallised grains is taken to be that of the fully recrystallised material and mathematically described by a phenomenological primary creep rate equation [65], so that their gradual work hardening during creep is taken into account in the model, consistently with the significant amounts of creep strain at the end of tests (see Fig. 7). For the unrecrystallised grains, creep rates are assumed to be constant since work hardened grains, containing a high density of dislocations (see Fig. 5), deform much more slowly than recrystallised ones, and with an almost constant strain rate, at least during the incubation periods observed in this study. It could be argued when comparing data from stress relaxation tests, EBSD measurements after creep under $20 \mathrm{MPa}$ at $850^{\circ} \mathrm{C}$, and double hit tests at $950^{\circ} \mathrm{C}$ (see Section 3.1.4.), 
that applied stress could have affected the recrystallisation kinetics. To address this issue, and in view of the small amount of available data on the stress sensitivity of static recrystallisation kinetics, the volume fraction of recrystallised grains is only expressed in the model as a function of temperature and time, by the JMAK relation (Eq. 3) using the experimentally calibrated parameters.

The predicted primary creep results of recrystallised (annealed) and of recrystallising samples at $850^{\circ} \mathrm{C}$ (Condition A) and $950^{\circ} \mathrm{C}$ (Condition B) under an engineering stress of $47 \mathrm{MPa}$ are shown in Figs 10a and 10b, respectively, together with the corresponding experimental data. In Fig. 10a, the predicted primary creep curves of the recrystallised material show good agreement with experiment at $950^{\circ} \mathrm{C}$; they somehow underestimate the experimental strain rate at $850^{\circ} \mathrm{C}$ between 100 and $300 \mathrm{~s}$. From the results shown in Fig. $10 \mathrm{~b}$ for the recrystallising material, it can be seen that at the beginning of recrystallisation, the predicted creep rate is rather low because the material behaviour is dominated by that of unrecrystallised grains. As recrystallisation proceeds, the volume fraction of recrystallised grains increases and so does the creep rate, dominated by the primary creep regime of newly recrystallised grains. Consequently, increases in strain rates are produced during recrystallisation until the material is fully recrystallised. Once fully recrystallised, the material exhibits a decreasing primary creep rate. The overall trend of the predicted curves is in good qualitative agreement with the experimental data.
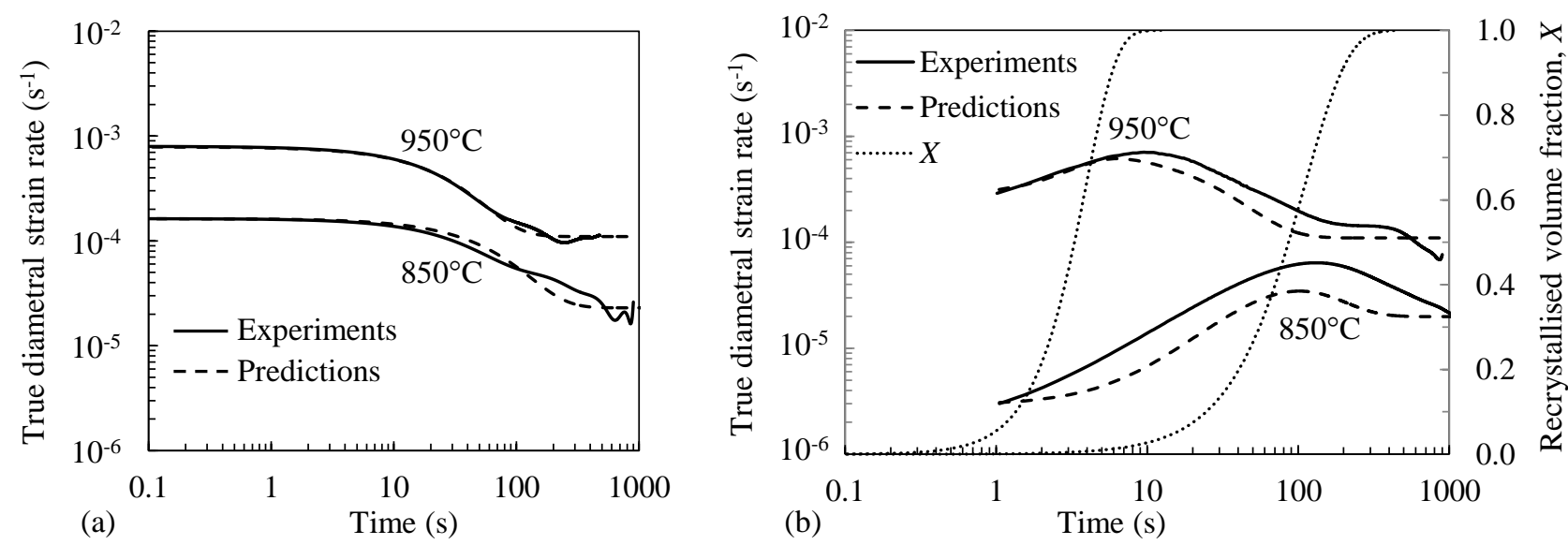

Fig. 10. Comparison between the measured and predicted creep strain rates under an engineering stress of $47 \mathrm{MPa}$ in the (a) recrystallised and (b) recrystallising materials, superimposed with the recrystallisation kinetics curve $(X)$

From the above results, it can be concluded that a significant contribution of viscoplastic deformation of recrystallised grains to the overall viscoplastic deformation is confirmed all along the creep tests, as proposed by Gifkins [18]. Furthermore, this recrystallisation-assisted deformation is, for the first time, qualitatively predicted using a phenomenological model with reasonable accuracy. However, it is important to note that in this model, the assumption of uniform stress may not be realistic enough, in particular for low fractions of recrystallised grains that are isolated from each other. This assumption 
can actually result in an overestimate of the strain rate at the beginning of recrystallisation, because the stress experienced by soft, freshly recrystallised grains is limited by the shielding exerted by the surrounding unrecrystallised, harder grains. In addition to this assumption, the potential effect of residual and internal stresses is not taken into account due to lack of experimental data. It is known that internal stresses can eventually impede the development of viscoplastic deformation $[66,67]$ and thus neglecting them may lead to an overestimate of recrystallised grains contribution to the average deformation of the recrystallising material. Nevertheless, the results reported in Fig.10 reveal that the model underestimates the strain rate, typically by a factor of two at $850^{\circ} \mathrm{C}$. This is despite of the fact that the recrystallisation kinetics described by the JMAK equation, as well as the micromechanical assumptions previously discussed have a tendency to overestimate the EBSD results (e.g., after 90s as seen in Figure 3) and thus the contribution of recrystallised grains to the viscoplastic deformation. This suggests that additional mechanisms might also contribute to recrystallisation-induced viscoplasticity.

\subsubsection{Other possible mechanisms}

It should be noted that increases in strain rate have also been observed in the present work during the incubation stage of recrystallisation (e.g. for times $t<15 \mathrm{~s}$ in Fig. 7a). As stress relaxation already occurs during this period (Fig. 2), probably as a result associated with thermally activated recovery phenomena, then it is appropriate to consider a contribution leading to "recovery-assisted viscoplasticity". As a consequence, the resistance/strength of unrecrystallised grains to undergo viscoplastic deformation decreases due to a decrease in the dislocation density driven by recovery processes. Consequently, the creep strength of unrecrystallised grains would probably no longer satisfy the constant value assumed by the model at each temperature during recrystallisation (see Table 1). Nevertheless, the dislocation density of deformed grains was still high and polygonisation inside them was not clearly revealed by TEM even during recrystallisation (Fig. 5). Consequently, the contribution of recovery-assisted viscoplasticity to the deformation of the recrystallising material is, if at all, expected to be low compared to that of the recrystallised material.

In addition to the above discussed contributions, stress-driven grain boundary migration (SDBM) [6870] can be another potential source of deformation during recrystallisation. A shear stress applied parallel to a grain boundary can induce not only conventional grain boundary sliding but also normal grain boundary motion [68]. Coupling between shear strain and normal migration of grain boundaries under local (internal) stresses has been evidenced and modelled in a variety of materials, either finegrained or bicrystals [68-73]. During growth of recrystallised grains, the normal velocity of migrating boundaries is high, but SDBM is believed to involve local atomic rearrangement without requiring long-range diffusion (e.g., [71]), so that its kinetics might be compatible with that of grain growth. At the "local" scale of one grain boundary, coupling between boundary migration and shear (by up to a 
few percent, see [71]) as well as its thermal activation strongly depend on the grain boundary structure and orientation with respect to the applied load [70]. Numerical simulations by atomistic or molecular dynamics calculations cannot cover timescales that are relevant to creep [73]. To the authors' knowledge, neither experimental evidence nor numerical modelling quantitatively reported the contribution of SDBM to macroscopic deformation of polycrystals. As such, even if SDBM might be important enough at low applied stresses to induce additional deformation during recrystallisation, its contribution to total strain, if any [68], cannot be quantified yet.

\section{Concluding Remarks}

An experimental study was performed to investigate and understand the recrystallisation-assisted viscoplastic deformation of an austenitic alloy under conditions approaching those of first stages of hot finishing rolling. The most important findings can be summarized as follows. Firstly, the effect of stress on the recrystallisation kinetics was found to be low when work hardened $\mathrm{Fe}-36 \% \mathrm{Ni}$ recrystallised at elevated temperatures. Secondly, the contribution of the deformation of newly recrystallised grains during primary creep to the overall viscoplastic deformation of a recrystallising material, composed of an evolving population of recrystallised and unrecrystallised grains, is significant. Furthermore, it has been shown that this recrystallisation-assisted deformation can be qualitatively predicted with acceptable accuracy using a phenomenological model of that contribution. Finally, during recrystallisation, other mechanisms, such as stress-driven grain boundary migration can potentially result in additional sources of visco-plastic deformation.

\section{Acknowledgments}

The authors are very grateful to Campus France for its financial support (PROCORE Program, grant No. 27128QL), to Aperam-Imphy for providing the material, to Professor André Pineau from MINES ParisTech for helpful and fruitful discussions, to Drs Eliette Mathey and Nicolas Legrand from ArcelorMittal and to Ph.D. student Zhiyuang Liang from Hong Kong University for their scientific and technical assistance. This study was supported by ArcelorMittal and by the French National Research and Technology Association (ANRT) through CIFRE contract No. 2010/884.

\section{References}

1. C. Roucoules, P.D. Hodgson, S. Yue, J.J. Jonas, Softening and microstructural change following the dynamic recrystallization of austenite, Metall. Mater. Trans. 25A (1994) 389400 . 
2. A. Dehghan-Manshadi, M.R. Barnett, P.D. Hodgson, Hot deformation and recrystallization of austenitic stainless steel: Part II. Post-deformation recrystallization, Metall. Mater. Trans. 39A (2008) 1371-1381.

3. A.M. Elwazri, E. Essadiqi, S. Yue, Kinetics of metadynamic recrystallization in microalloyed hypereutectoid steels, ISIJ Int. 44 (2004) 744-752.

4. R.A.P. Djaic, J.J. Jonas, Static recrystallization of austenite between intervals of hot working, J. Iron Steel Inst. 210 (1972) 256-261.

5. R.A.P. Djaic, J.J Jonas, Recrystallisation of high carbon steel between intervals of hightemperature deformation, Metall. Trans. 4 (1973) 621-624.

6. C.M. Sellars, J.A. Whiteman, Recrystallization and grain growth in hot rolling, Met. Sci. 13 (1979) 187-194.

7. A. Rollett, F.J. Humphreys, G.S. Rohrer, M. Hatherly, Recrystallisation and related annealing phenomena, 2nd edition, Pergamon Press, Oxford, 2004.

8. T. Poirier, G. Cayuela, B. Petit, P. Rahier, J.M. Suret, S. Petit, F. Dehouck, M. Blondel, ArcelorMittal internal report, 1998.

9. Y. Hoshi, M. Kitahama, M. Hokada, H. Yoneda, H. Shiomi, Y. Fujii, Automatic width control system using interstand tension in hot strip finishing mill, Rev. Metall. 93 (1996) 1413-1420.

10. P. Montmitonnet, P. Gratacos, R. Ducloux, Application of anisotropic viscoplastic behaviour in 3D finite-element simulations of hot rolling, J. Mater. Proc. Technol. 58 (1996) 201-211.

11. N. Rudkins, P. Evans, Mathematical modelling of mill set-up in hot strip rolling of high strength steels, J. Mater. Proc. Technol. 80-81 (1998) 320-324.

12. E. Hadasik, R. Kuziak, R. Kawalla, M. Adamczyk, M. Pietrzyk, Rheological model for simulation of hot rolling of new generation steel strips for automotive applications, Steel Res. Int. 77 (2006) 927-933.

13. Y.-M. Liu, G.-S. Ma, D.-W. Zhao, D.-H. Zhang, Analysis of hot strip rolling using exponent velocity field and MY criterion, Int. J. Mech. Sci. 98 (2015) 126-131.

14. E.P. Busso, A continuum theory for dynamic recrystallization with microstructure-related length scales, Int. J. Plast. 14 (1998) 319-353.

15. M. Huang, P.E.J. Rivera-Díaz-del-Castillo, O. Bouaziz, S. van der Zwaag, Modelling the steady state deformation stress under various deformation conditions using a single irreversible thermodynamics based formulation, Acta Mater. 57 (2009) 3431-3438.

16. S.B. Lee, R.A. Lebensohn, A.D. Rollett, Modeling the viscoplastic micromechanical response of two-phase materials using Fast Fourier Transforms, Int. J. Plast. 27 (2011) 707-727.

17. A.A. Smith, Jr., Creep and recrystallization of lead, American Institute of Mining and Metallurgical Engineers, STP No. 1227 (1940) 1-7.

18. R.C. Gifkins, Recrystallization of lead during creep, J. Inst. Met. 87 (1958-1959) 255-261.

19. D. Hardwick, C.M. Sellars, W.J. Mc Tegart, The occurrence of recrystallization during high- 
temperature creep, J. Inst. Met. 90 (1961) 21-22.

20. G.J. Richardson, C.M. Sellars, W.J. Mc Tegart, Recrystallization during creep of nickel, Acta Metall. 14 (1966) 1225-1236.

21. Y.-C. Cheng, M. Chauhan, F.A. Mohamed, Uncovering the mystery of Harper-Dorn creep in metals, Metall. Trans. A 40A (2009) 80-90.

22. T.J. Ginter, P.K. Chaudhury, F.A. Mohamed, An investigation of Harper-Dorn creep at large strains, Acta Mater. 49 (2001) 263-272.

23. T.J. Ginter, F.A. Mohamed, Evidence for dynamic recrystallization during Harper-Dorn creep, Mater. Sci. Eng. A322 (2002) 148-152.

24. A.J. Ardell, Harper-Dorn creep - The dislocation network theory revisited, Scr. Mater. 69 (2013) 541-544.

25. H.N. Han, S.J. Kim, M. Kim, G. Kim, D.W. Suh, S.J. Kim, Diffusion-controlled recrystallization and grain growth-induced plasticity of steel under externally applied stress, Philos. Mag. 88 (2008) 1811-1824.

26. E.I. Estrin, Recrystallization-induced plasticity, Phys. Metals Metallogr. 102 (2006) 324-327.

27. B. Hutchinson, O. Rod, M. Nylén, A. Carlsson, A. Oskarsson, Mechanisms of sagging during brazing of aluminium heat exchangers, in: Proceedings of the 12th International Conference on Aluminium Alloys, The Japan Institute of Light Metals, Tokyo, 2010 (6 pages).

28. M.X. Huang, A. Pineau, O. Bouaziz, T.D. Vu, Recrystallization induced plasticity in austenite and ferrite, Mater. Sci. Eng, A541 (2012) 196-198.

29. L. Ben Mostefa, G. Saindrenant, M.P. Solignac, J.P. Colin, Effect of interfacial sulfur segregation on the hot ductility drop of FeNi36 alloys, Acta Mater. 39 (1991) 3111-3118.

30. Y. Yanchong, C. Weiqing, Z. Hongguang, Research on the hot ductility of Fe-36Ni Invar alloy, Rare Metals Mater. Eng. (English edition) 43 (2014) 2969-2973.

31. X. Li, N. Chen, J. Li, X. He, H. Liu, X. Zheng, J. Chen, Effect of temperature and strain rate on deformation behavior of Invar 36 alloy, Acta Metall. Sin. 53 (2017) 968-974.

32. S.M. Abbasi, M. Morakabati, R. Mahdavi, A. Momeni, Effect of microalloying additions on the hot ductility of cast FeNi36, J. Alloys Compounds 639 (2015) 602-610.

33. S.H. Cho, S.I. Kim, Y.C. Yoo, Determination of "no-recrystallization" temperature of Invar alloy by fractional softening measurement during the multistage deformation, J. Mater. Sci. Lett. 16 (1997) 1836-1837.

34. S. He, C.-S. Li, Z.-Y. Huang, J.-J. Zheng, A modified constitutive model based on Arrheniustype equation to predict the flow behavior of Fe-36\%Ni Invar alloy, J. Mater. Res. 32 (2017) 3831-3841.

35. S. Hishiyama, Y. Honda, D. Sato, H. Tanabe, Effects of cold rolling and annealing conditions on recrystallization and r-value in Invar alloy, Testu-to-hagane 81 (1995) 67-72.

36. T. Sato, Y. Tashiro, Y. Honda, M. Nishida, A. Chiba, The influence of cold-rolling reduction on 
r-value and recrystallization behavior in Fe-36Ni alloy, ISIJ. Int. 38 (1998) 640-646.

37. S. Zaefferer, T. Baudin, R. Penelle, A study on the formation mechanisms of the cube recrystallization texture in cold-rolled Fe-36\%Ni alloys, Acta Mater. 49 (2001) 1105-1122.

38. F. Caleyo, T. Baudin, R. Penelle, V. Venegas, EBSD study of the development of cube recrystallization texture in Fe-50\%Ni, Scr. Mater. 45 (2001) 413-420.

39. T. Baudin, F. Julliard, R. Penelle, Recrystallization texture development by multiple twinning in $(\mathrm{Fe}-36 \% \mathrm{Ni})$ Invar, Rev. Met. CIT/Science et Génie des Matériaux (Now: Metallurgical Research and Technology) 100 (2003) 193-202 (in French).

40. R. Penelle, Nucleation and growth during primary recrystallization of certain metals and alloys with a face-centered cubic structure: Formation of the cube texture, Int. J. Mater. Res. 100 (2009) 1420-1432.

41. R. Penelle, T. Baudin, Primary recrystallization of Invar, Fe-36\%Ni alloy: Origin and development of the cubic texture, Adv. Eng. Mater. 12 (2010) 1047-1052.

42. K. Tirsatine, H. Azzeddine, T. Baudin, A.L. Helbert, F. Brisset, D. Bradai, On the recrystallization and texture of $\mathrm{Fe}-36 \% \mathrm{Ni}$ alloy after accumulative roll bonding and annealing at $600^{\circ} \mathrm{C}$, Materials Engineering (Materiálové inžinierstvo) 24 (2017) 46-56.

43. B.J Han, Microstructure characterization of hot deformed Fe-32\%Ni Alloy, Adv. Mater. Res. 230-232 (2011) 154-158.

44. S. Vervynckt, K. Verbeken, P. Thibaux, Y. Houbaert, Characterization of the austenite recrystallization comparing double deformation and stress relaxation tests, Steel Res. Int. 81 (2010) 234-244.

45. L.P. Karjalainen, Stress-relaxation method for investigation of softening kinetics in hot deformed steels, Mater. Sci. Technol. 11 (1995) 557-565.

46. K. Okazaki, M. Kagawa, Y. Aono, Analysis of thermally activated flow in an Fe-0.056 at percent Ti alloy using stress relaxation, Z. Metallk. 67 (1976) 47-56.

47. A.S. Taylor, P.D. Hodgson, The post-deformation recrystallization behaviour of 304 stainless steel following high strain rate deformation, Mater. Sci. Eng. A529 (2011) 164-169.

48. T. Sakai, M. Ohashi, K. Chiba, J.J. Jonas, Recovery and recrystallization of polycrystalline nickel after hot-working, Acta Metall. 36 (1988) 1781-1790.

49. W.A. Johnson, R.F. Mehl, Reaction kinetics in processes of nucleation and growth, Trans. AIME 135 (1939) 416-442.

50. J. Avrami, Granulation, phase change, and microstructure - kinetics of phase change. III, J. Chem. Phys. 9 (1941) 177-184.

51. A.N. Kolmogorov, Statistical theory of crystallization of metals, Bull. Acad. Sci. USSR, Phys. Ser. (Engl. Transl.) 3 (1937) 355-359.

52. C. Devadas, I.V. Samarasekera, E.B. Hawbolt, The thermal and metallurgical state of steel strip during hot-rolling 3. Microstructural evolution, Metall. Trans. 22A (1991) 335-349. 
53. M. Džubinský, Z. Husain, W.M. van Haaften, Comparison of recrystallisation kinetics determined by stress relaxation, double hit, optical metallography and EBSD approaches, Mater. Charact. 52 (2004) 93-102.

54. H. Luo, J. Sietsma, S. van der Zwaag, Effect of inhomogeneous deformation on the recrystallization kinetics of deformed metals, ISIJ Int. 44 (2004) 1931-1936.

55. H.J. Frost, M.F. Ashby, Deformation-mechanism maps, Pergamon Press, New York, 1982.

56. M. Winning, C. Schafer, Influencing recrystallization behaviour by mechanical loads, Mater. Sci. Eng. A419 (2006) 18-24.

57. P.H. Thornton, R.W. Cahn, The recovery and recrystallization of copper and aluminium under stress, J. Inst. Met. 89 (1961) 455-463.

58. J.S. Perttula, L.P. Karjalainen, Recrystallisation rates in austenite measured by double compression and stress relaxation methods, Mater. Sci. Technol. 14 (1998) 626-630.

59. V.D. Vijayanand, P. Parameswaran, M. Nandagopal, S. Panneer Selvi, K. Laha, M.D. Mathew, Effect of prior cold work on creep properties of a titanium modified austenitic stainless steel, J. Nucl. Mater. 438 (2013) 51-57.

60. G. Trotter, G. Rainer, I. Baker, P.R. Munroe, Accelerated precipitation in the AFA stainless steel Fe-20Cr-30Ni-2Nb-5Al via cold working, Intermetallics 53 (2014) 120-128.

61. A. Mehmanparast, C.M. Davies, D.W. Dean, K. Nikbin, Effects of plastic pre-straining level on the creep deformation, crack initiation and growth behaviour of $316 \mathrm{H}$ stainless steel, Int. J. Pressure Vess. Piping 141 (2016) 1-10.

62. M.-H. Jang, J.-Y. Kang, J.H. Jang, T.-H. Lee, C. Lee, Microstructure control to improve creep strength of alumina-forming austenitic heat-resistant steel by pre-strain, Mater. Charact. 137 (2018) 1-8.

63. S. Chomette, J.-M. Gentzbittel, B. Viguier, Creep behaviour of as received, aged and cold worked INCONEL 617 at $850^{\circ} \mathrm{C}$ and $950^{\circ} \mathrm{C}$, J. Nucl. Mater. 399 (2010) 266-274.

64. R.L. Coble, Sintering crystalline solids 2. Experimental test of diffusion models in powder compacts, J. Appl. Phys. 32 (1961) 793-799.

65. F. Garofalo, Resistance to creep deformation and fracture in metals and alloys, in: Properties of crystalline solids, ASTM STP 283 (1960) 82-98.

66. A.S. Argon, A.K. Bhattacharya, Primary creep in nickel: experiments and theory, Acta Metall. 35 (1987) $1499-1514$.

67. C.K.L. Davies, S. Poolay-Mootien, R.N. Stevens, Internal stress and unloading experiments in creep, J. Mater. Sci. 27 (1992) 6715-6724.

68. J.W. Cahn, Y. Mishin, A Suzuki, Coupling grain boundary motion to shear deformation, Acta Mater. 54 (2006) 4953-4975.

69. T. Gorkaya, D.A. Molodov, G. Gottstein, Stress-driven migration of symmetrical $<100\rangle$ tilt grain boundaries in Al bicrystals, Acta Mater. 57 (2009) 5396-5405. 
70. D.A. Molodov, T. Gorkaya, G. Gottstein, Migration of the $\Sigma 7$ tilt grain boundary in Al under an applied external stress, Scr. Mater. 65 (2011) 990-993.

71. F. Mompiou, D. Caillard, M. Legros, Grain boundary shear-migration coupling-I. In situ TEM straining experiments in Al polycrystals, Acta Mater. 57 (2009) 2198-2209.

72. D. Caillard, F. Mompiou, M. Legros, Grain-boundary shear-migration coupling. II. Geometrical model for general boundaries, Acta Mater. 57 (2009) 2390-2402.

73. D. Farkas, Atomistic simulations of metallic microstructures, Current Opinion in Solid State and Materials Science 17 (2013) 284-297.

\section{Appendix: Modelling the contribution of recrystallised grains to the acceleration of viscoplastic deformation}

The recrystallising material is assumed to be composed of recrystallised and unrecrystallised grains, which are in turn considered to deform under uniform stress conditions. The average viscoplastic strain rate is given as,

$\dot{\varepsilon}^{v p}(t)=(1-X(t)) \dot{\varepsilon}_{\text {unrex }}+\int_{0}^{t} \dot{X}\left(t^{\prime}\right) \dot{\varepsilon}_{\text {rex }}\left(t-t^{\prime}\right) d t^{\prime}$

where, $X$, is the volume fraction of recrystallised grains, and $\dot{\varepsilon}_{\text {unrex }}$ and $\dot{\varepsilon}_{\text {rex }}$ are the viscoplastic strain rates of unrecrystallised and recrystallised grains, respectively. In order to keep the model as simple as possible, thermal strains were not taken into account as the tests were carried out at constant temperature. Note that the time, $t$, is set to zero at the beginning of the creep test, that is, after the predeformation stage illustrated in Fig. 1b. At a given time $t$, any recrystallised grain appeared at time $t$ ', $t^{\prime}<t$, is supposed to have immediately begun to deform, so that its strain rate is calculated for a creep time ( $\left.t-t^{\prime}\right)$, leading to the second term of eq. (A.1). The time evolution of $X$ obeys the JMAK relation (eq. 2), and the parameters $t_{50 p c t}$ and $n$ are calibrated from the data shown in Fig. 3a. In eq. (A.1), $\dot{\varepsilon}_{\text {unrex }}$ is constant and its value is taken as the strain rate at the beginning of the creep test, before the onset of recrystallisation. Also, $\dot{\varepsilon}_{\text {rex }}$ is assigned to be the flow behaviour of the fully recrystallised material, determined from delayed creep tests, and described as in [34],

$$
\ddot{\varepsilon}_{r e x}=-\frac{1}{\tau}\left(\dot{\varepsilon}_{r e x}-\dot{\varepsilon}_{r e x}^{S S}\right), \dot{\varepsilon}_{r e x}(t=0)=\dot{\varepsilon}_{i} \text {, so that } \dot{\varepsilon}_{r e x}=\dot{\varepsilon}_{r e x}^{S S}+\left(\dot{\varepsilon}_{i}-\dot{\varepsilon}_{r e x}^{S S}\right) \exp \left(-\frac{t}{\tau}\right)
$$

where, $\tau$, is a characteristic time constant obtained by fitting model predictions to the experimental primary creep curves of Fig. 7(a). The steady-state strain rate, $\dot{\varepsilon}_{\text {rex }}^{S S}$, is given by a power-law equation of the form [30]:

$\dot{\varepsilon}_{\text {rex }}^{s S}=A \frac{D_{v} \mu b}{k T}\left(\frac{\sigma}{\mu}\right)^{N}$

where, $\sigma$, is the applied stress, $D_{v}=D_{0} \exp \left(-Q_{v} / R T\right)$ is the lattice diffusion coefficient, and $A, D_{0}$, and $Q_{v}$, are material constants, $\mu$ is the shear modulus, and $b$ the magnitude of the Burgers vector. As there 
is no available experimental steady-state creep data for $\mathrm{Fe}-36 \% \mathrm{Ni}$, their values were taken from data on pure nickel [30]. All model parameters are given in Table 1.

\section{Table 1. Model parameters}

\begin{tabular}{|c|c|c|c|c|c|c|c|c|c|c|c|}
\hline $\begin{array}{c}T \\
\left({ }^{\circ} \mathrm{C}\right)\end{array}$ & $\begin{array}{l}t_{50 p c t} \\
(\mathrm{~s})\end{array}$ & $n$ & $\begin{array}{c}\dot{\varepsilon}_{\text {unrex }} \\
\left(\mathrm{s}^{-1}\right)\end{array}$ & $\begin{array}{c}\dot{\varepsilon}_{i} \\
\left(10^{-4} \mathrm{~s}^{-1}\right)\end{array}$ & $\begin{array}{l}\tau \\
(\mathrm{s})\end{array}$ & $A$ & $\begin{array}{c}D_{0} \\
\left(\mathrm{~m}^{2} / \mathrm{s}\right)\end{array}$ & $\begin{array}{c}\mu \\
(\mathrm{GPa})\end{array}$ & $\begin{array}{c}b \\
\left(10^{-10} \mathrm{~m}\right)\end{array}$ & $N$ & $\begin{array}{c}Q_{v} \\
(\mathrm{~kJ} / \mathrm{mol})\end{array}$ \\
\hline 850 & 86 & 1.5 & $1.76 \times 10^{-6}$ & 1.6 & 75 & & & & & 4.58 & \\
\hline 950 & 3.2 & 2.1 & $2.5 \times 10^{-4}$ & 7.9 & 25 & $3 \times 10^{6}$ & $1.9 \times 10^{-4}$ & 54.8 & 2.49 & 4.7 & 284 \\
\hline
\end{tabular}

